\title{
Corpos em aliança: Diálogos interseccionais
}

\author{
MARTINS, Ana Claudia; VERAS, Elias Ferreira. Corpos em Aliança: Diálogos \\ Interdisciplinares sobre gênero, raça e sexualidade. I. ed. Curitiba: Appris, 2020.
}

\section{Crislanne Maria dos Santos*}

Nas últimas décadas, temos testemunhados constantes transformações sociais, históricas, políticas e culturais, que abalaram as estruturas cishetonormativas dos antigos padrões de gênero, raça e sexualidade. As lutas feministas, as conquistas LGBTQIA+, os movimentos trabalhistas e a descolonização dos países africanos, por exemplo, que perpassaram o século passado, desdobrando-se até os dias atuais, culminam em novas formas contemporâneas de fazer política e ciência.

A obra Corpos em Aliança: Diálogos Interdisciplinares sobre gênero, raça e sexualidade, organizada por Elias Ferreira Veras e Ana Claudia Aymoré Martins, professor/a da Universidade Federal de Alagoas (UFAL), aparece nesse contexto teórico-metodológicopolítico de transformações, sendo oriundo dos debates realizados durante o II Colóquio diálogos interdisciplinares sobre gênero, raça e sexualidade: corpos em aliança, organizado pelo Grupo de Estudos e Pesquisas em História, Gênero e Sexualidade (GEPHGS/CNPq), do Curso de História da UFAL - com apoio do CNPq -, em Maceió (AL), no mês de maio de 2019.

O livro propõe um diálogo interdisciplinar e interseccional, tornando-se necessário para todos/as aqueles/as que tem como objeto de preocupação acadêmico-política, o gênero, a raça e a sexualidade. Já em seu título, os/as organizadores/as explicitam a aliança com o pensamento da filósofa norte-americana Judith Butler, particularmente, seu livro Corpos em Aliança e a política das ruas (Civilização Brasileira, 20I8), no qual Butler debate sobre a construção de alianças coletivas. Levantando questões sobre feminismo, classe, raça e sexualidade, os textos da coletânea atualizam o debate, interseccionando teorias de

\footnotetext{
" Mestranda em História pelo Programa de Pós-Graduação em História (PPGH), da Universidade Federal de Alagoas (UFAL), onde desenvolve pesquisa sobre prostituição feminina em Maceió, nas décadas de I970-1980. É integrante do Grupo de Estudos e Pesquisas em História, Gênero e Sexualidade (GEPHGS/CNPq). E-mail: crislanne.santos@outlook.com
} 


\section{C) Gitistór RICA}

maneira a melhor compreender as atuais dinâmicas sociais que resultam, por exemplo, na violência de gênero, transfobia, homofobia, racismo, exploração de classe, precariedade neoliberal etc.

Dividida em onze capítulos, a obra contempla textos de pesquisadoras/es de diversas áreas do conhecimento, como História, Direito, Filosofia, Serviço Social, Letras, entre outros. É composta ainda, pelo poema "Sobrevivência”, de autoria da atriz e escritora transfeminista Ísis Florescer, o que confere ao livro um toque literário singular. Mais que do que poesia, "Sobrevivência" é um grito de alguém que insiste em (re) existir em um mundo transfóbico.

A tradução Mapeando as Margens: Interseccionalidade, políticas identitários e violências contra mulheres de cor, de Kimberlé Crenshaw abre a coletânea. Neste texto clássico, somente agora traduzido para o português do Brasil, Crenshaw mostra como "a intersecção de raça e gênero moldam, de maneira estrutural, política e representacional, os aspectos da violência contra as mulheres de cor" (Crenshaw, 2020, p. 27). De acordo com a autora, as mulheres de cor estão situadas de maneira desigual nas esferas econômicas, sociais e políticas, ocupando uma posição interseccional entre os homens de cor e as mulheres brancas. Crenshaw explicita como as mulheres de cor estão à margem dos discursos que permeiam os debates sobre racismo e feminismo, uma vez que, o primeiro foi urdido contra a exploração de raça sofrida por homens de cor, enquanto o segundo, a subordinação e exploração de gênero sofrida por mulheres brancas. Desta forma, a autora mostra como as teorias de raça e gênero convergiram, até então, para a marginalização das mulheres de cor na sociedade e sua posição de tripla subordinação: aos homens brancos, negros e às mulheres brancas. Vemos ainda, nesse texto fundante dos estudos interseccionais, como as mulheres de cor são mais intensamente afetadas pela dominação de raça e gênero, pela violência sexual e doméstica. E ainda, pelas problemáticas socioeconômicas, sendo elas as mais vulneráveis às situações de desemprego e subemprego.

O lugar da raça em tempos de ação afirmativa, de Jeferson Santos da Silva, Leandro da Silva Rosa e Sérgio da Silva Santos, integrantes do Instituto do Negro de Alagoas/INEG, aborda as raízes do racismo estrutural no Brasil. Os autores discutem como o processo de colonização e escravidão moldou nossa sociedade neoliberal, branca e meritocrata, afetando a existência e efetivação de políticas públicas voltadas para as populações negras no Brasil. 


\section{C) HitsistórRICA}

No capítulo seguinte, Novas relações de poder e resistências: Corpos em aliança como resistência à precariedade neoliberal, Cristiane Marinho articula as ideias de Michel Foucault, Pierre Dardot, Christian Laval e Judith Butler para problematizar a precariedade e a resistência na sociedade neoliberal. Utilizando-se da análise foucaultiana sobre o poder, Marinho analisa o advento e consolidação do neoliberalismo, bem como, as novas formas de resistência nesse contexto. Em diálogo com Butler, a autora traz o conceito de precariedade, para mostrar como nessas novas formas de poder neoliberais, precários são todos/as aqueles/as cuja humanidade é apagada e negada, em todas as suas modalidades (raça, gênero, classe, sexualidade).

No quarto capítulo da obra, Elaine Pimentel discorre sobre A violência sexual compreendida pelas lentes da interseccionalidade. Pimentel dialoga com Kimberlé Crenshaw, Carla Akotirene e Patrícia Hill Collins, para analisar a realidade multifacetada da violência de gênero, que oprime mulheres e todos aqueles/as que não se enquadram no padrão cisheteronormativo. A autora demostra, desse modo, as diferentes faces da violência de gênero, permeadas também pela classe e raça.

No capítulo seguinte, Capitalismo, patriarcado e denominação masculina e a subjugação feminina, Andreia Pacheco de Mesquita e Gildete Ferreira da Silva, problematizam a apropriação do corpo feminino pelo poder patriarcal capitalista, explicitando como a modernização conservadora subalterniza as mulheres, sobrecarregando-as com as funções domésticas, o que as autoras denominam de "fenômeno da mulher caracol", ou seja, mulheres que trabalham fora de casa, mas cujas responsabilidades do lar continuam sob sua responsabilidade. Conforme Mesquita e Silva, essas mulheres foram autorizadas a adentrar no mercado de trabalho sem, contudo, serem donas de seu corpo e de sua vida.

No sétimo capítulo, (Re)inventando o corpo do sodomita no Medievo Ibérico, Marcelo Pereira Lima realiza um acurado estudo sobre a sodomia medieval. Lima constrói seu texto procurado esclarecer as formas histórico-político-institucionais da sodomia medieva, que além de crime, também é pecado, "um ato repugnante ao homem honesto". Trabalhando a partir de textos jurídicos que foram produzidos no território Ibero-português, o historiador analisa, a partir da perspectiva de gênero, como a sexualidade e as dimensões homoeróticas foram representadas nas obras jurídicas medievais, analisando, desse modo, as modalidades de violência que permeavam a práticas sexuais masculinas. 


\section{C) Gitistór RICA}

Maria Aparecida de Oliveira Lopes, por sua vez, em Expressões de Gênero e Corpo na Arte Africana, utiliza o conceito de Interseccionalidade, situando seu debate na perspectiva da arte negra no mundo pós colonial, articulando os conceitos de raça e classe, bem como, o de gênero, centrando sua análise sobre as trajetórias de artistas africanas para debater questões que permeiam corpo, gênero, trabalho e identidade na produção artística negra.

No capítulo Mutação genética e agência feminista em THE EVENING AND TTHE MORNING AND THE NICHT de Octavia Butler, Joan Haran e Ildney Cavalcanti, refletem sobre gênero, genética e eugenia no conto da escritora americana Octavia Butler. As autoras centram sua análise na construção distópica literária de Butler e no modo como a escritora negra norte-americana articula gênero e ciência em uma sociedade separada por uma mutação genética. Ciência, mutação, genética e feminismo são centrais na análise literária construída por Cavalcanti e Haran.

Os dois últimos capítulos do livro foram reservados a seus organizadores, Elias Ferreira Veras e Ana Claudia Aymoré Martins. Em Foucault, Butler, Preciado e Davis na oficina da história, Veras discorre sobre como a teoria queer, as reflexões de Foucault e a teoria feminista negra, possibilitaram a construção de sua análise das experiencias trans no Brasil. Ao revistar sua tese, publicada com o título Travestis: carne, tinta e papel (2020), o autor mostra a importância de compreender, não apenas a dimensão do gênero e da sexualidade no estudo sobre as experiencias das trans, mas, também como raça e classe se interseccionam na produção das subjetividades trans.

Já Ana Claudia Aymoré Martins em Câmara Obscura: Abjeção e transgressão dos corpos nas obras de José Danoso e Nilton Resende, último texto da coletânea, analisa duas obras nas quais as personagens principais são mulheres trans: Manuela, personagem principal da obra de José Danoso, O lugar sem limites (1966); e a personagem inominada de Nilton Resende, de um dos contos de Diabolô (20II). Assim, tomando como aporte teórico Julia Kristeva, Judith Butler e Judith Halberstam, Martins discute os temas da transgressão e objeção dos corpos trans na literatura contemporânea, problematizando a construção das identidades da pessoa trans e, ainda, a marginalidade e objetificação que estes sujeitos e seus corpos estão submetidos.

Em Corpos em Aliança e a política das ruas, obra que inspirou a obra resenhada, Butler debate sobre o direito de aparecer, como algo negado às vidas precárias, ou seja, as minorias sexuais, de gênero e raça. Estas minorias, cuja precariedade se materializa em 


\section{C) HițTó RICA}

seus corpos, são relegadas às margens, criminalizadas pelo Estado e coisificadas pelo capitalismo, precisam atuar em conjunto no espaço das ruas, dando voz às suas demandas e construindo a democracia. Desse modo, os corpos em aliança emergem da necessidade das diferentes vozes se unirem e construírem uma nova democracia.

Assim sendo, gostaria de salientar a importância desses corpos em alianças em diálogos interseccionais, especialmente, nesse contexto de crescimento da extrema direita e sua produção de discursos racistas, machistas, misóginos, LGBTfóbicos, endossados por uma pauta neoliberal, cuja centralidade se estabelece na coisificação e capitalização dos sujeitos. A obra resenhada nos ajuda a analisar as dimensões atuais políticas, sociais, culturais do nosso país e a problematizar os discursos que emergem do embate políticoideológico brasileiro e ainda a pensar estratégias de união e politização de nossas ações como forma de promover uma democracia radicalmente democrática. Democracia esta em que as diferenças sejam respeitadas e todas as vidas sejam valorizadas, não pelo valor monetário empregado pelo neoliberalismo cisheteronormativo, mas das vidas dignas de serem vividas em igualdade e liberdade. 